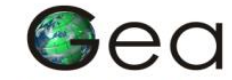

JURNAL PENDIDIKAN GEOGRAFI

\title{
PENGARUH ELEMEN EKOWISATA TERHADAP KEPUTUSAN BERKUNJUNG WISATAWAN KE TAMAN HUTAN RAYA IR. H. DJUANDA
}

\author{
Rima Sophal Jamil, Bagja Waluya \\ Departemen Pendidikan Geografi, FPIPS, UPI, email: bagjawaluya@upi.edu
}

\begin{abstract}
Forest tourism always improve itself to be better as like as the progressive of sustainable tourism and tourist has knew to go back to nature. The sustainable tourism well going on it is the ecotourism. One of the ecotourism area who famous is it Ir.H.Djuanda grand forest park. As a nature-based tourism Ir.H.Djuanda grand forest park need strategy to increase number of visit's, they using elements of ecotourism strategy. Elements of ecotourism as independent variable $(X)$ is nature, education and sustainability, and dependent variable $(Y)$ is visit decision. Sustainable and education differentiating ecotourism from "nature-based tourism". This type of research was descriptive verificative research and sampling methode use was systematic random sampling with the amount of sampling was 100 domestic tourist who has visited Ir.H.Djuanda grand forest park. Techniques of data analysis and hypothesis testing used was multiple linear regression analysis. The result showed that the dimension of the element of ecotourism education and visit decision dimension on purchase timing at the lowest score if we compared to other dimension. However it can be concluded that the elements of ecotourism Ir.H.Djuanda grand forest park and the visit decision to Ir.H.Djuanda grand forest park in the category of avarage, and also elements of ecotourism has influence the visit decision.
\end{abstract}

Keyword : ecotourism, visit decision, grand forest park.

\section{PENDAHULUAN}

Saat ini pariwisata tidak hanya sebagai kegiatan bersenang-senang, dengan kesadaran dari berbagai pihak, pariwisata saat ini menjadi lebih perduli terhadap keberlanjutan berbagai sumber daya yang ada terutama sumber daya alam yang tak terbarukan. Hutan-hutan wisata terus berkembang seiring berkembangnya pariwisata berkelanjutan dan kesadaran wisatawan untuk lebih dekat dengan alam, bukan hanya sekedar mengeksploitasi kekayaan alam tetapi juga ikut melestarikan kekayaan alam agar dapat dinikmati oleh generasi selanjutnya. Pariwisata berkelanjutan yang saat ini sedang berkembang adalah ekowisata,

Pariwisata pada saat ini tidak hanya sebagai kegiatan bersenang-senang yang memberikan dampak buruk, akan tetapi pariwisata menjadi suatu industri yang dapat memberikan banyak dampak yang positif. Pariwisata yang memberikan banyak dampak positif dikenal dengan istilah Sustainable Tourism (Pariwisata Berkelanjutan). UNWTO (2013:10) mendefinisikan pariwisata berkelanjutan sebagai pariwisata yang memperhitungkan penuh dampak ekonomi, sosial dan lingkungan saat ini dan masa depan, serta dapat mengatasi kebutuhan pengunjung, industri, lingkungan dan masyarakat setempat.

Ekowisata merupakan bagian dari pariwisata berkelanjutan yang berpijak kepada tiga wisata sekaligus, yaitu wisata pedesaan, wisata alam dan wisata budaya. Menurut Iwan Nugroho (2011:17), ekowisata merupakan kegiatan wisata yang menaruh perhatian yang sangat besar terhadap kelestarian lingkungan, budaya serta kesejahteraan masyarakat setempat. ekowisata adalah kegiatan perjalanan wisata yang dikemas secara professional, terlatih dan memuat unsur pendidikan, 
sebagai suatu sektor/usaha ekonomi, yang mempertibangkan warisan budaya, partisipasi dan kesejahteraan penduduk lokal serta upaya konservasi sumber daya alam dan lingkungan.

Menurut Lee, Lawton dan Weaver (2013:520), ada tiga karakteristik utama yang membangun ekowisata dan telah disetujui, yaitu : 1) Nature, yaitu daya tarik wisata yang berbasis alam, dan biasanya fokus pada ekosistem yang relatif tidak terganggu atau memiliki endemik yang masih asli seperti megafauna karismatik (misalnya, panda raksasa, koala, crane rejan) yang menghuni ekosistem tersebut, megaflora karismatik (misalnya, pohon kayu merah) dan megalith (misalnya, gunung berapi, tebing) yang ditampilkan. (Weaver 2008); 2) Education, wisatawan yang datang memiliki motivasi untuk belajar yang berkisar dari interaksi pendidikan formal untuk estetika atau spiritual. On-site interpretasi disediakan melalui beragam bentuk seperti pusat pengunjung, pemandu wisata, signage permanen, dan buku panduan; 3) Sustainability, ekowisata adalah pretensi formal untuk pariwisata berbasis keberlanjutan. Dalam jangka praktis, ini memerlukan kepatuhan terhadap perencanaan dan manajemen yang berusaha untuk meminimalkan dampak terhadap lingkungan, sosial budaya, dan ekonomi yang terkait sekaligus memaksimalkan manfaat yang terkait(Buckley 2002).

Menurut Kotler \& Amstrong (2012: 133) mengatakan bahwa "Consumer buyer behavior merupakan perilaku pembelian konsumen akhir/individu dan rumah tangga yang membeli barang dan jasa untuk konsumsi pribadi. Kotler \& Keller (2012:161) menyatakan bahwa elemen keputusan berkunjung terdiri dari Product choice, Brand choice, Dealer choice, Purchase amount dan Purchase timing.

Hipotesis dalam penelitian ini adalah terdapat pengaruh antara elemen ekowisata yang terdiri dari nature, education dan sustainability terhadap keputusan berkun- jung wisatawan. Hipotesis ini didukung dengan premis yang dinyatakan Eugene E. Ezebilo (2014:10) "Ecotourism is a responsible travel to natural areas that conserves the environment and improves the well-being of local people. It involves visits to destinations where animals, plants and cultural heritage are the main attractions".

Sarah \& Claire (2013:28) mengungkapkan bahwa "Ecotourists choose their destination in accordance with the types of products offered, generally they are looking for specific experiences they cannot reach in other areas. Therefore providing a high value product and services is very important.

Sedangkan Vinerean Alexandra (2013: 193) mengatakan "Personal determinants of tourist behavior are: circumstances: health, disposable income, leisure time, family commitments, work commitment, knowledge of destinations, the availability of different tourism products, price differences between competitor organizations, attitudes and perceptions, perceptions of destinations and tourism organizations, political views, preferences for particular countries and cultures, their attitudes to standards of behavior as a tourist, experience of: types of holidays, different destinations, taking a trip with particular individuals or groups."

Ekowisata menjadi perpaduan dari berbagai minat yang tumbuh dari keprihatinan terhadap lingkungan, ekonomi dan sosial. Jawa Barat memiliki berbagai potensi wisata alam yang melimpah, salah satunya hutan wisata yang menjadi kawasan ekowisata yaitu Taman Hutan Raya (selanjutnya disebut TAHURA) Ir. H. Djuanda. TAHURA Ir. H. Djuanda merupakan salah satu kawasan konservasi yang memiliki akses yang mudah dan memiliki daya tarik wisata yang beragam serta unik.. Dengan beragamnya daya tarik wisata yang dimiliki menjadi penarik wisatwan untuk berkunjung.

Tabel 1 menunjukan kunjungan wisatawan ke TAHURA Ir. H. Djuanda terus mengalami peningkatan hingga tahun 2012, namun pada tahun 2014 jumlah kunjungan wisatawan mengalami 
penurunan sebesar $16 \%$ bila dibandingkan tahun 2012, suatu penurunan yang cukup signifikan bila dibandingkan dengan tahun sebelumnya. Hal ini disebabkan karena berbagai faktor seperti bermunculannya daerah tujuan wisata baru hingga beralihnya minat wisatawan menjadi wisata belanja dan kuliner.

Tabel 1. Jumlah Kunjungan Wisatawan ke TAHURA Ir. H. Djuanda

\begin{tabular}{ccc}
\hline No & Tahun & Jumlah Wisatawan \\
\hline 1 & 2010 & 125,084 \\
\hline 2 & 2011 & 135,722 \\
\hline 3 & 2012 & 140,412 \\
\hline 4 & 2013 & 158,677 \\
\hline 5 & 2014 & 131,805 \\
\hline
\end{tabular}

Sumber : Balai Pengelolaan Taman Hutan Raya Ir $\mathrm{H}$ Djuanda, 2014

Sebagai daya tarik wisata berbasis alam TAHURA Ir. H. Djuanda tidak hanya menyediakan keindahan alam sebagai atraksi wisatanya, tetapi juga atraksi wisata pendidikan juga wisata keberlanjutan. Kegiatan wisata yang didalamnya terdiri dari alam, pendidikan serta keberlanjutan adalah ekowisata. Menurut Lee, Lawton dan Weaver (2013:520), ekowisata saat ini telah disetujui memiliki tiga karakteristik utama, yaitu : Nature, Education, and Sustainability. Kriteria sustainable dan education bersama-sama membedakan ekowisata dari "pariwisata berbasis alam", yang merupakan istilah umum untuk pariwisata yang mengandalkan alam.

Berdasarkan latar belakang tersebut, maka perlu dilakukan suatu penelitian tentang "Pengaruh Elemen Ekowisata Terhadap Keputusan Berkunjung Wisatawan Ke Taman Hutan Raya Ir. H. Djuanda".

\section{METODE PENELITIAN}

Penelitian ini akan menganalisis tentang pengaruh elemen ekowisata terhadap keputusan berkunjung wisatawan ke TAHURA Ir. H. Djuanda. Yang menjadi variable bebas atau independent variable $(\mathrm{X})$ dalam penelitian ini adalah elemen ekowisata yang terdiri dari nature, education dan sustainability, sedangkan yang menjadi variable terikat atau dependent variable $(\mathrm{Y})$ adalah keputusan berkunjung wisatawan. Penelitian ini akan dilakukan di TAHURA Ir. H. Djuanda dengan unit analisis adalah wisatawan nusantara yang berkunjung ke TAHURA Ir. H. Djuanda. Selain itu penelitian ini dilakukan kurang dari satu tahun, maka jenis metode yang digunakan yaitu cross sectional methode.

Berdasarkan tingkat penjelasan dan bidang penelitian, maka jenis penelitian ini adalah penelitian deskriptif dan verifikatif dengan menggunakan metode explanatory survey untuk memperoleh gambaran tentang elemen ekowisata dan keputusan berkunjung. Populasi dalam penelitian ini ialah wisatawan nusantara yang datang berkunjung ke TAHURA Ir. H. Djuanda, dengan jumlah sampel menggunakan rumus Slovin yaitu sejumlah 100 responden. Teknik sampling yang digunakan ialah probability sampling khususnya simple random sampling dan teknik pengumpulan data yang dilakukan terdiri dari wawancara, observasi dan kuesioner (angket). Analisis data dalam penelitian ini menggunakan teknik analisis regresi berganda (multiple regression).

\section{HASIL DAN PEMBAHASAN}

Berdasarkan hasil penelitian yang dilakukan maka diperoleh gambaran tanggapan responden terhadap elemen ekowisata. Perolehan nilai tertinggi pada elemen ekowisata adalah dimensi nature dengan skor sebesar 350,00 atau 35,26\%. Alam merupakan daya tarik wisata utama kawasan ini, wisatawan yang datang ingin menikmati keindahan alam yang masih asli dan jauh dari kebisingan perkotaan. Sedangkan untuk skor terendah terdapat pada dimensi education dengan skor 314,43 atau sebesar $31,67 \%$. Fasilitas wisata edukasi masih kurang menunjang kegiatan wisata yang dilakukan dan masih kurang lengkap. Secara keseluruhan, gambaran elemen ekowisata pada garis kontinum berada pada kategori cukup. 
Untuk keputusan berkunjung, skor tertinggi terdapat pada brand choice dengan skor 371,00 atau sebesar 22,35\%. Skor terendah terdapat pada purchase timing dengan skor sebesar 290,50 atau 17,50\%. Untuk gambaran keputusan berkunjung, secara keseluruhan pada garis kontinum berada pada kategori cukup.

Pengujian hipotesis (uji F/Anova) diperoleh dengan mebandingkan nilai $F_{\text {hitung }}$ dengan $F_{\text {tabel }}, F_{\text {hitung }}(73,573)$ lebih besar dari $F_{\text {tabel }}(2,699)$ dan nilai signifikansi juga sangat kecil yaitu sebesar 0,000 dan lebih kecil dari 0,05 yang berarti lolos uji signifikan. Maka dapat disimpulkan bahwa Ho ditolah dan Ha diterima yang artinya elemen ekowisata yang terdiri dari nature, education dan sustainability berpengaruh terhadap keputusan berkunjung.

Berdasarkan hasil penelitian yang dilakukan melalui uji $t$, dari 3 dimensi mendapatkan hasil signifikansi kurang dari 0,05 . Berdasarkan uji tersebut dapat dilihat bahwa nilai thitung $\left(X_{1}=6,336 ; X_{2}=6,622\right.$; $\left.X_{3}=5,441\right)$ lebih besar dari $t_{\text {tabel }}(1,985)$. Maka dapat disimpulkan bahwa elemen ekowisata yang terdiri dari nature, education dan sustainability mempunyai pengaruh terhadap keputusan berkunjung.

Berdasarkan hasil perhitungan, persamaan regresi berganda untuk pengaruh elemen ekowisata terhadap keputusan berkunjung dirumuskan sebagai berikut:

\section{$Y=a+b_{1} X 1+b_{2} X 2+b_{3} X 3$}

$Y=-0,076+0,359 X_{1}+0,318 X_{2}+0,265 X_{3}$

Dari persamaan regresi yang diperoleh dapat dijelaskan bahwa konstanta (intersept) sebesar -0,076 menunjukkan apabila Nature, Education dan Sustainability tidak berubah atau pada kondisi konstan (bernilai 0), maka rata-rata keputusan berkunjung akan bernilai -0,076. Ini berarti jika semua elemen ekowisata diabaikan maka nilai keputusan berkunjung negatif.

\section{SIMPULAN}

Berdasarkan penelitian dapat disimpulkan bahwa tanggapan responden wisatawan nusantara mengenai gambaran elemen ekowisata di TAHURA Ir. H. Djuanda termasuk dalam kategori "cukup". Elemen ekowisata dimensi nature memiliki rata-rata skor paling tinggi, adapun item yang memiliki skor tertinggi pada dimensi nature adalah keindahan pemandangan alam TAHURA Ir. H. Djuanda sedangkan untuk skor terendahnya ada pada item keragaman koleksi fauna yang dimiliki oleh TAHURA Ir. H. Djuanda. Sedangkan elemen ekowisata dimensi education memiliki rata-rata skor terendah, skor tertinggi pada dimensi education terdapat pada item kejelasan informasi pada papan interprettasi, dan skor terendah pada dimensi education terdapat pada item kejelasan informasi pada buku panduan.

Tanggapan responden wisatawan nusantara mengenai gambaran keputusan berkunjung ke TAHURA Ir. H. Djuanda termasuk kedalam kategori "cukup". Berdasarkan hasil pengolahan data, dapat diketahui bahwa dimensi keputusan berkunjung yang memiliki rata-rata skor tertinggi terdapat pada brand choice. Untuk rata-rata skor terendah terdapat pada dimensi purchase timing.

Berdasarkan hasil penelitian yang telah dilakukan, maka dapat disimpulkan bahwa tanggapan responden wisatawan nusantara mengenai pengaruh elemen ekowisata yang terdiri dari nature, education dan sustainability terhadap keputusan berkunjung ke TAHURA Ir. H. Djuanda berpengaruh signifikan, baik secara simultan maupun parsial.

Berdasarkan penelitian yang telah dilakukan, disarankan agar pengelola TAHURA Ir. H. Djuanda meningkatkan dimensi education dengan cara meningkatkan wisata edukasi yang ada serta meningkatkan berbagai fasilitas untuk penunjang kegiatan wisata edukasi. Selain itu diensi nature dan sustainability yang sudah mendapat tanggapan baik dari wisatawan harus terus dipertahankan dan dijaga, disarankan agar pengelola terus melakukan pemeliharaan agar tetap baik 
atau bahkan menjadi lebih baik. Pengelola juga harus menghimbau agar wisatawan dapat turut serta menjaga lingkungan kawasan TAHURA Ir. H. Djunada.

Meningkatkan jumlah kunjungan wisatawan pada saat weekday juga menjadi saran selanjutnya untuk pengelola. Dalam rangka meningkatkan kunjungan wisatawan pada saat weekday, pengelola disarankan melakukan promosi baik ke sekolah-sekolah maupun perkantoran untuk melakukan kunjungan pada saat weekday, menyelenggarakan berbagai event yang diadakan di TAHURA Ir. H. Djuanda pada saat weekday. Fasilitas outbound dan lintas alam dapat dijadikan penarik minat wisatawan untuk berkunjung ke TAHURA ini pada saat weekday. Dengan melakukan pembuatan paket wisata berupa paket lintas alam dan outbound untuk kegiatan teamwork building dan character building.

\section{DAFTAR PUSTAKA}

Alexandra Vinerean. (2013). Consumer Behavior In Tourism And The Influencing Factors of The Decision Making Process. Sibiu: Revista Economica

Balai Pengelolaan Taman Hutan Raya Ir H Djuanda.
Eugene E. Ezebilo. (2014). Choosing Ecotourism Destinations for Vacations: A Decision-Making Process.Sweden: Asian Social Science; Vol. 10, No. 2; 2014 SSN 1911-2017 E-ISSN 1911-2025

Iwan Nugroho. (2011). Ekowisata dan Pembangunan Berkelanjutan. Yogyakarta: Pustaka Pelajar

Philip Kotler, Gary Amstrong. (2012). Principles of Marketing. Prentice Hall: New Jersey

Philip Kotler, Kevin Lane Keller. (2012). Marketing Management $14^{\text {th }}$ ed. New Jersey: Prentice Hall

Pitana,I Gde dan Diarta, I Ketut Surya. (2009). Pengantar Ilmu Pariwisata. Yogyakarta: Andi.

Poupineau Sarah dan Pouzadoux Claire. (2013). Internal and External Factors That Influence The Ecotourist.School of Business and Engineering:Halmstad University

UNWTO. (2013). Sustainable Tourism for Development Guidebook.Madrid:UNWTO

Young-Sook Lee, Laura J. Lawton dan David B.Weaver. (2013). Evidence for a South Korean Model of Ecotourism. Journal of Travel Research 52(4) 520-533. 